\title{
Efficacy of an implantable cardioverter-defibrillator in patients with diabetes and heart failure and reduced ejection fraction
}

\author{
Rasmus Rørth $^{1,2}$. Pooja Dewan ${ }^{1}$. Søren Lund Kristensen ${ }^{1,2}$ - Pardeep S. Jhund ${ }^{1} \cdot$ Mark C. Petrie $^{1} \cdot$ Lars Køber $^{2}$. \\ John J. V. McMurray ${ }^{1}$
}

Received: 26 November 2018 / Accepted: 17 January 2019 / Published online: 28 January 2019

(c) The Author(s) 2019

\begin{abstract}
Background The effect of implantable cardioverter-defibrillator (ICD) therapy in patients with heart failure with reduced ejection fraction (HFrEF) and diabetes is not fully elucidated.

Methods We examined the effect of ICD therapy on sudden cardiac death, cardiovascular death and all-cause mortality, according to diabetes status at baseline in the Sudden Cardiac Death in Heart Failure Trial (SCD-HeFT). The outcomes were analyzed by use of cumulative incidence curves and Cox regressions models.

Results Of the 1676 patients randomized to an ICD or placebo, 540 (32\%) had diabetes at baseline. Patients with diabetes were slightly older (61 vs 58 years) and were more often in NYHA class III ( $37 \%$ vs $28 \%$ ). ICD therapy did not reduce the risk of sudden cardiac death in HFrEF patients with diabetes (HR $=0.85 ; 95 \% \mathrm{CI} 0.52-1.40)$; even though these patients had a higher risk of sudden cardiac death compared to patients without diabetes (HR=1.73 95\% CI 1.22-2.47). By contrast, ICD therapy did reduce sudden cardiac death in HFrEF patients without diabetes $\left(\mathrm{HR}=0.26\right.$; 95\% CI 0.15-0.46); $P_{\text {interaction }}=0.002$. The findings for cardiovascular and all-cause death were similar.

Conclusion ICD therapy did not reduce the risk of sudden cardiac death (or, as a consequence, all-cause death) in HFrEF patients with diabetes. Conversely, an ICD reduced the risk of sudden death in patients without diabetes, irrespective of etiology.
\end{abstract}

Keywords Implantable cardioverter-defibrillator $\cdot$ Heart failure with reduced ejection fraction $\cdot$ Diabetes $\cdot$ Sudden cardiac death

\section{Introduction}

Patients with heart failure, reduced ejection fraction (HFrEF) and diabetes have a higher risk of adverse cardiovascular outcomes compared to HFrEF patients without diabetes [1-3]. This elevated risk includes a higher rate of sudden, presumed arrhythmic, cardiac death $[4,5]$. Use of

Electronic supplementary material The online version of this article (https://doi.org/10.1007/s00392-019-01415-z) contains supplementary material, which is available to authorized users.

John J. V. McMurray

john.mcmurray@glasgow.ac.uk

1 British Heart Foundation Cardiovascular Research Centre, University of Glasgow, 126 University Place, Glasgow G12 8TA, UK

2 Rigshospitalet Copenhagen University Hospital, Copenhagen, Denmark an implantable cardioverter-defibrillator (ICD) has been shown to reduce the risk of sudden cardiac death, and overall mortality, in patients with HFrEF. However, there is less certainty about the benefit of an ICD in patients with a nonischemic etiology compared to those with an ischemic etiology $[6,7]$. Patients with an ischemic etiology have a higher risk of sudden death than those with a non-ischemic etiology $[6,7]$. The effect of ICD therapy in HFrEF patients with diabetes, with and without underlying ischemic heart disease, has not been described, although this is clearly an important question given the frequent overlap between HFrEF and diabetes, the potentially different response to therapy in HFrEF patients with diabetes and the especially high risk of sudden death faced by individuals with both diabetes and an ischemic etiology. We examined these questions in the Sudden Cardiac Death in Heart Failure Trial (SCD-HeFT), the single large trial which demonstrated the benefit of this 
therapy in patients with HFrEF due to both ischemic and non-ischemic causes.

\section{Methods}

\section{Study design and population}

The design and primary results of SCD-HeFT are published [6]. In brief, in SCD-HeFT, 2521 patients in New York Heart Association (NYHA) functional class II or III, with a left ventricular ejection fraction (LVEF) $\leq 35 \%$, were randomly assigned to placebo, amiodarone or ICD therapy in a 1:1:1 ratio. ICD therapy, but not amiodarone, reduced the primary endpoint of all-cause death. We used the public-use copy of the SCD-HeFT database obtained from the National Heart, Lung, and Blood Institute which sponsored the trial.

\section{Definition of diabetes and etiology}

For this analysis, patients were categorized according to whether they had a history of diabetes/were treated with glucose-lowering drugs at baseline or not. Ischemic or nonischemic etiology was determined by the investigators.

\section{Outcomes}

The primary endpoint of this study was that used in SCDHeFT, i.e., all-cause mortality. Cardiovascular death, sudden cardiac death, and death due to heart failure were evaluated as secondary outcomes. Outcomes were evaluated according to HF etiology, NYHA class, and estimated glomerular filtration rate (eGFR)

\section{Statistical analysis}

Baseline characteristics according to diabetes status were described using proportions for categorical variables and mean values with standard deviations or medians with quartiles for continuous variables. Differences in baseline characteristics according to diabetes status were tested by use of $\chi^{2}$-test for categorical variables and ANOVA or Kruskal-Wallis's test for continuous variables. Changes in LVEF were summarized by use of medians with quartiles and differences evaluated by use of quantile regression adjusted for baseline values. Kaplan-Meier curves for allcause mortality and cumulative incidence curves for cardiovascular death and sudden cardiac death were estimated and differences between groups were compared by log rank and Gray's test, respectively. Cox proportional hazard models were used to compare the risk according to diabetes status for all death-related outcomes. The adjusted Cox regression models included information on age, gender, randomization to ICD implantation, NYHA class, LVEF, duration of heart failure, heart failure etiology, systolic blood pressure, creatinine, history of atrial fibrillation, stroke and pulmonary disease. $\log [-\log$ (survival)] curves were used to evaluate the proportional hazard assumption. Diabetes status, heart failure etiology and NYHA class were tested for interactions with randomization to ICD implantation in relation to all outcomes. The interaction of eGFR and treatment effect according to diabetes status on all-cause mortality was analyzed by multivariable fractional polynomials with extension for interactions.

$P$ values $<0.05$ were considered significant. Analyses were performed by Stata version 15 and $\mathrm{R}$ version 3.3.2.

\section{Results}

\section{Baseline characteristics}

Of the 1676 patients randomized to an ICD or placebo, 540 (32\%) had diabetes at baseline. Patients with diabetes were slightly older (61 vs 58 years), were more often in NYHA class III ( $37 \%$ vs $28 \%$ ), had worse kidney function (median eGFR: 68 vs $71 \mathrm{~mL} / \mathrm{min}$ per $1.73 \mathrm{~m}^{2}$ ), and higher weight ( $89 \mathrm{vs} 84 \mathrm{~kg}$ ), compared to those without diabetes (Table 1). History of hypertension ( $68 \%$ vs $50 \%$ ), myocardial infarction ( $76 \%$ vs $71 \%$ ), stroke ( $8 \%$ vs $6 \%$ ) and treatment with diuretics $(89 \%$ vs $81 \%)$ was more common among patients with diabetes. These findings remained consistent when patients in the amiodarone arm of the trial were added (Supplementary table 1).

\section{Complications during ICD implantation}

Patients with diabetes had similar risk of ICD-related infections and a lower risk of bleeding and pneumothorax than patients without diabetes. Specifically, infection complicated implantation in $20(3.5 \%)$ patients without diabetes, compared to $9(3.1 \%)$ patients with diabetes $(p=0.76)$; the respective numbers for bleeding were $29(5.1 \%)$ vs. $4(1.5 \%)$, $p=0.02$ and for pneumothorax $9(1.6 \%)$ vs. $0(0 \%), p=0.04$.

\section{Change in left ventricular ejection fraction after randomization}

Patients with diabetes had a slightly but significantly higher LVEF at baseline, compared to patients without diabetes, and also marginally but significantly greater increase in LVEF during follow-up: median change from baseline to 12 months $(n=1159)+4$ [IQR $0.0,12.5]$ in patients without diabetes and $+5[-1.0,12.5]$ in patients with diabetes, $p=0.004$; the corresponding changes at 30 months $(n=777)$ were: $+5[0.0,15.0]$ vs $+6[0.0,16.0]$, respectively, 
Table 1 Baseline characteristics of patients in the placebo and ICD group

\begin{tabular}{|c|c|c|c|}
\hline & No diabetes & Diabetes & $P$ values \\
\hline Patients, $n(\%)$ & $1136(68)$ & $540(32)$ & \\
\hline Age, median [Q1-Q3] & $58\left[\begin{array}{ll}50 & 68\end{array}\right]$ & $61[53,68]$ & 0.0095 \\
\hline Men, $n(\%)$ & $883(78)$ & $411(76)$ & 0.4606 \\
\hline White, $n(\%)$ & $890(78)$ & $393(73)$ & 0.0218 \\
\hline ICD implantation, $n(\%)$ & $570(50)$ & $259(48)$ & 0.3971 \\
\hline NYHA class III, $n(\%)$ & $314(28)$ & $202(37)$ & 0.0001 \\
\hline Ischemic heart failure etiology, $n(\%)$ & $551(49)$ & $333(62)$ & 0.0001 \\
\hline Left ventricular ejection fraction, median [Q1-Q3] & $23.5[19,30]$ & $25[20,30]$ & 0.0074 \\
\hline Systolic blood pressure, mmHg, median [Q1-Q3] & $117[104,130]$ & $120.0[108.0,135.0]$ & 0.0011 \\
\hline Diastolic blood pressure, mmHg, median [Q1-Q3] & $70[62,80]$ & $70[60,80]$ & 0.3732 \\
\hline Weight, Kg, median [Q1-Q3] & $84[73,98]$ & $89[77,104]$ & 0.0001 \\
\hline Heart rate, beats/min, median [Q1-Q3] & $72[64,83]$ & $77[68,86]$ & 0.0001 \\
\hline eGFR, mL/min/1.73 $\mathrm{m}^{2}$, median [Q1-Q3] & $71[57,85]$ & $68[52,82]$ & 0.0007 \\
\hline \multicolumn{4}{|l|}{ Medical history, $n(\%)$} \\
\hline Atrial fibrillation/flutter & $170(15)$ & $88(16)$ & 0.4803 \\
\hline Hypertension & $564(50)$ & $367(68)$ & 0.0001 \\
\hline Myocardial infarction & $478(71)$ & $282(76)$ & 0.0402 \\
\hline Stroke & $64(6)$ & $45(8)$ & 0.0362 \\
\hline Pulmonary disease & $213(19)$ & $120(22)$ & 0.0959 \\
\hline \multicolumn{4}{|l|}{ Medication $^{\mathrm{a}}, n(\%)$} \\
\hline $\mathrm{ACE}$ inhibitor or $\mathrm{ARB}$ & $1093(96)$ & $517(96)$ & 0.641 \\
\hline B-Blocker & $788(69)$ & $369(68)$ & 0.6691 \\
\hline Mineralocorticoid-receptor antagonist & $210(19)$ & $107(20)$ & 0.5162 \\
\hline Diuretic & $923(81)$ & $480(89)$ & 0.0001 \\
\hline Digoxin & 763 (67) & 378 (70) & 0.2447 \\
\hline Insulin & $0(0)$ & 198 (37) & - \\
\hline Oral hypoglycemic agents & $0(0)$ & $325(60)$ & - \\
\hline
\end{tabular}

Q-quartile, $I C D$ implantable cardioverter defibrillator, $A C E$ angiotensin-converting enzyme, $A R B$ angiotensin-receptor blocker, $e G F R$ estimated glomerular filtration rate

${ }^{a}$ At baseline $p=0.005$. As a result, $32.5 \%$ of patients with diabetes (compared to $30.0 \%$ without diabetes) had a LVEF $>35 \%$ after approximately 12 months of follow-up and $40 \%$ (compared with $36 \%$ ) at 30 months.

\section{Clinical outcomes according to diabetes status}

During a median follow-up of 46 months (Q1-Q3:35-55), sudden cardiac death occurred in $63(12 \%)$ patients with diabetes and $71(6 \%)$ without. Death from cardiovascular causes occurred in $128(24 \%)$ patients with diabetes and in 161 (14\%) patients without; 187 (35\%) patients with diabetes died from any cause, compared to 239 (21\%) patients without diabetes. In adjusted analyses, diabetes was associated with a higher risk of sudden cardiac death $(\mathrm{HR}=1.7395 \%$ CI 1.22-2.47; $p=0.002)$, cardiovascular death $(\mathrm{HR}=1.52$; 95\% CI 1.19-1.93; $p=0.001)$ and all-cause mortality $(\mathrm{HR}=1.50 ; 95 \%$ CI $1.23-1.83 ; p<0.0001)$; Table 2 .

\section{Effect of ICD therapy according to diabetes status}

ICD therapy did not reduce the risk of sudden cardiac death in HFrEF patients with diabetes ( $\mathrm{HR}=0.85 ; 95 \%$ CI 0.52-1.40). By contrast, ICD therapy did reduce sudden cardiac death in HFrEF patients without diabetes $(\mathrm{HR}=0.26 ; 95 \%$ CI $0.15-0.46) ; P_{\text {interaction }}=0.002$. The effects of ICD therapy on any cardiovascular death and death from heart failure are shown in Fig. 1. Examining all-cause mortality, 84 patients $(32 \%)$ with diabetes died in the ICD group compared to 103 patients $(37 \%)$ with diabetes in the placebo group; $\mathrm{HR}=0.94 ; 95 \% \mathrm{CI}$ $0.70-1.25 ; p=0.65$ (Fig. 2). Among those without diabetes, 98 patients $(17 \%)$ died in the ICD group, compared to 141 patients $(25 \%)$ without diabetes in the placebo group; $\mathrm{HR}=0.68 ; 95 \%$ CI $0.52-0.88 ; p=0.003$ (Fig. 2), $\mathrm{p}$ for interaction $=0.11$ (Fig. 1).

Patient level data on appropriate and inappropriate ICD discharges were not available. 
Table 2 Event rates and hazard ratios for all outcomes according to diabetes status of patients in the placebo and ICD group

\begin{tabular}{|c|c|c|c|c|c|c|}
\hline & Events (n) & $\begin{array}{l}\text { Crude rate per } 100 \\
\text { py }(95 \% \text { CI })\end{array}$ & Unadjusted HR (95\% CI) & $p$ values & Adjusted $\mathrm{HR}^{\mathrm{a}}(95 \% \mathrm{CI})$ & $p$ values \\
\hline \multicolumn{7}{|c|}{ All-cause mortality } \\
\hline Diabetes & 187 & $10.8(9.4-12.5)$ & $1.80(1.49-2.18)$ & $<0.0001$ & $1.50(1.23-1.83)$ & $<0.0001$ \\
\hline No diabetes & 239 & $6.1(5.3-6.9)$ & 1.00 (ref.) & & 1.00 (ref.) & \\
\hline \multicolumn{7}{|l|}{ CV death } \\
\hline Diabetes & 128 & $7.4(6.2-8.8)$ & $1.82(1.44-2.30)$ & $<0.0001$ & $1.52(1.19-1.93)$ & 0.001 \\
\hline No diabetes & 161 & $4.1(3.5-4.8)$ & 1.00 (ref.) & & 1.00 (ref.) & \\
\hline \multicolumn{7}{|c|}{ Sudden cardiac death } \\
\hline Diabetes & 63 & $3.7(2.9-4.7)$ & $2.02(1.44-2.83)$ & $<0.0001$ & $1.73(1.22-2.47)$ & 0.002 \\
\hline No diabetes & 71 & $1.8(1.4-2.3)$ & 1.00 (ref.) & & 1.00 (ref.) & \\
\hline \multicolumn{7}{|c|}{ Non-sudden CV death } \\
\hline Diabetes & 124 & $7.2(6.0-8.6)$ & $1.71(1.36-2.16)$ & $<0.0001$ & $1.42(1.11-1.80)$ & 0.005 \\
\hline No diabetes & 168 & $4.3(3.7-4.9)$ & 1.00 (ref.) & & 1.00 (ref.) & \\
\hline
\end{tabular}

$H R$ hazard ratio, $p y$ person years, $C V$ cardiovascular, ref reference

${ }^{a}$ Adjusted for age, gender, randomization to ICD implantation, NYHA class, left ventricular ejection fraction, duration of HF, HF etiology, systolic blood pressure, creatinine, history of atrial fibrillation, stroke and pulmonary disease

\section{Effect of ICD implantation according to diabetes status and kidney function}

The reduction in sudden cardiac death with an ICD was apparent in patients without diabetes, irrespective of kidney function, although attenuated in no-diabetes patients with chronic kidney disease (CKD) (Fig. 3 and Supplementary Fig. 1). By contrast, the effect of ICD therapy on sudden cardiac death in patients with diabetes was absent in patients with concomitant CKD and attenuated in those with preserved renal function, compared to no diabetes patients with an eGFR $>60 \mathrm{~mL} / \mathrm{min} / 1.73 \mathrm{~m}^{2}$ (Fig. 3). Similar findings were observed when eGFR was examined as a continuous variable (Supplementary Fig. 1).

All-cause mortality was lower in the ICD group, compared with the placebo group, in patients without diabetes, irrespective of renal function category. By contrast, ICD treatment did not clearly reduce all-cause mortality in patients with diabetes but without CKD. In patients with both diabetes and CKD, mortality was higher in the ICD group than in the placebo group (Fig. 3).

\section{Effect of ICD implantation according to diabetes status and ischemic vs. non-ischemic etiology}

The reduction in sudden cardiac death with an ICD was apparent in patients without diabetes, irrespective of etiology (Fig. 4). By contrast, there was no clear effect of ICD therapy on sudden cardiac death in patients with diabetes, whether the etiology of HFrEF was ischemic or nonischemic (Fig. 4). The effect of ICD therapy on sudden cardiac death was significantly modified by diabetes status overall, according to etiology and CKD status and in relation to NYHA class (Fig. 1).

All-cause mortality was lower in the ICD group, compared with the placebo group, in patients without diabetes, irrespective of etiology (ischemic vs. non-ischemic). By contrast, ICD treatment did not reduce all-cause mortality in patients with diabetes, irrespective of etiology.

\section{Effect of amiodarone according to diabetes status}

In the amiodarone group, 97 (39\%) with diabetes died compared to 103 (37\%) with diabetes in the placebo group; $\mathrm{HR}=1.19 ; 95 \% 0.90-1.57 ; p=0.22$; Fig. 1 . In patients without diabetes, 143 patients (24\%) died in the amiodarone group compared to 141 patients $(25 \%)$ without diabetes in the placebo group; $\mathrm{HR}=1.01 ; 95 \% \mathrm{CI} 0.80-1.27 ; p=0.96$ (Fig. 1).

\section{Effect of amiodarone according to diabetes status and ischemic vs. non-ischemic etiology}

Overall, the effect of amiodarone, compared with placebo, did not differ according to diabetes status, etiology, NYHA class or CKD status (Supplementary Fig. 2).

\section{Discussion}

In this retrospective subgroup analysis of SCD-HeFT, ICD therapy did not reduce the risk of sudden cardiac death, and therefore the risk of death from any cause, in HFrEF patients with diabetes although these patients were at high 
Fig. 1 Hazard ratios for the comparison of ICD therapy vs placebo
All Patients

All-cause mortality

Cardiovascular death Sudden cardiac death

Heart failure death

Ischemic etiology

All-cause mortality

Cardiovascular death

Sudden cardiac death

Heart failure death

Non-ischemic etiology

All-cause mortality

Cardiovascular death

Sudden cardiac death

Heart failure death

NYHA class II

All-cause mortality

Cardiovascular death

Sudden cardiac death

Heart failure death

NYHA class III

All-cause mortality

Cardiovascular death

Sudden cardiac death

Heart Failure death

$e G F R<60 \mathrm{~mL} / \mathrm{min} / 1.73 \mathrm{~m}^{2}$

All-cause mortality

Cardiovascular death

Sudden cardiac death

Heart Failure death

$e G F R \geq 60 \mathrm{~mL} / \mathrm{min} / 1.73 \mathrm{~m}^{2}$

All-cause mortality

Cardiovascular death

Sudden cardiac death

Heart Failure death

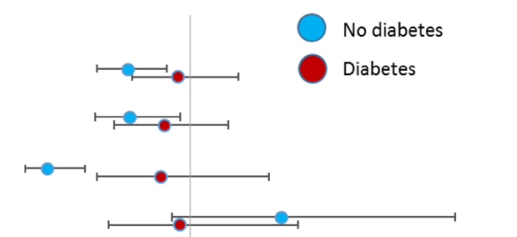

P value for interaction

0.11

0.37

0.002

0.20

0.59

0.87

0.01

0.05

0.05

0.21

0.06

0.89

0.22

0.75

0.01

0.22

0.61

0.09

0.29

0.08

0.09

0.02

0.93

0.09

0.07 

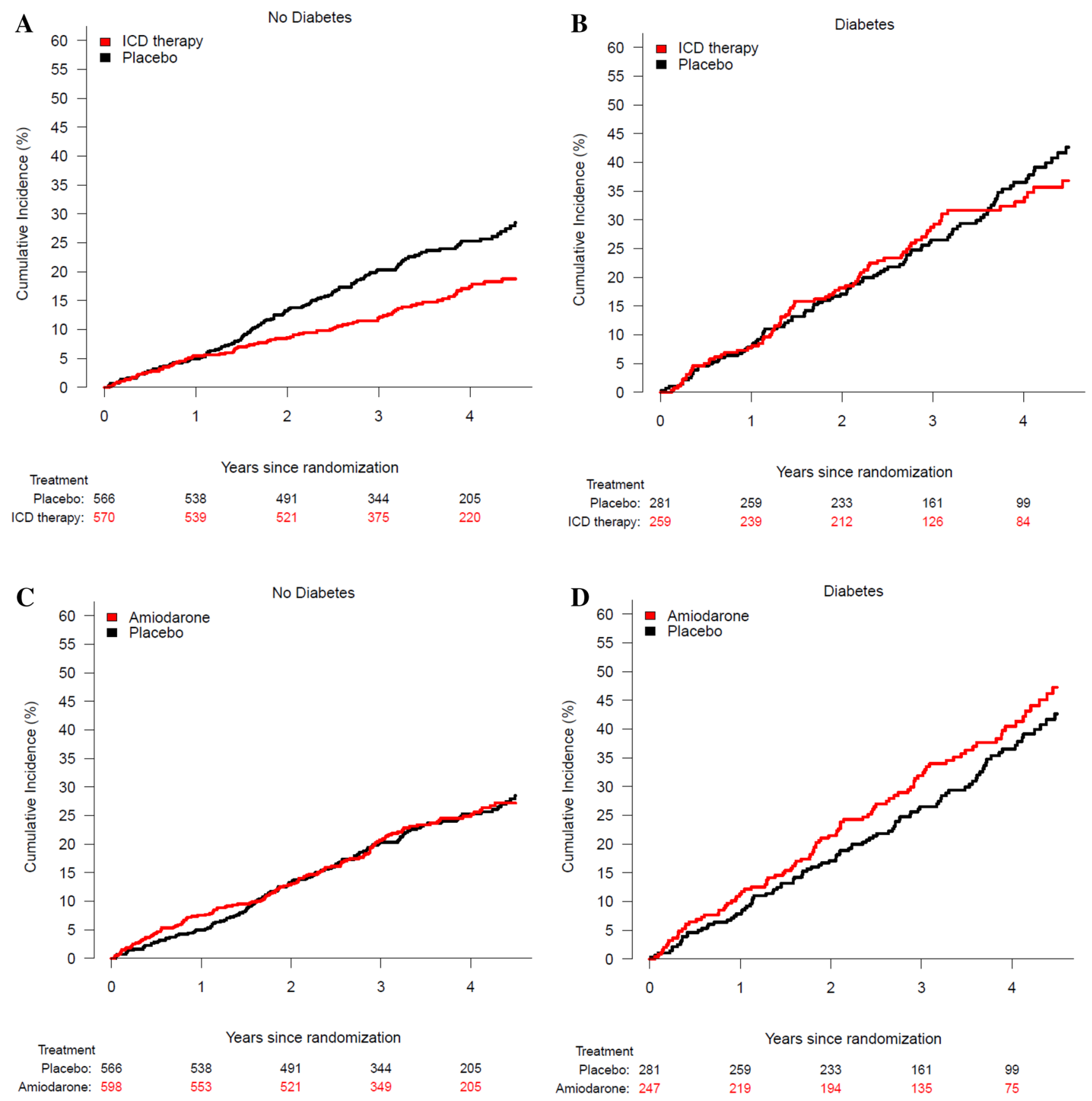

Fig. 2 Risk of death among patients with and without diabetes

risk of sudden, presumed arrhythmic, death. By contrast, ICD therapy did reduce the risk of sudden cardiac death, and all-cause mortality, in HFrEF patients without diabetes. This difference in outcomes with ICD therapy was not explained by etiology (ischemic versus non-ischemic) of HFrEF.

The explanation for the lack of mortality benefit in patients with diabetes is uncertain although the issue of competing risks needs to be considered as it is more relevant with an ICD than other therapies for heart failure and more relevant in patients with diabetes than in those without. Specifically, ICD therapy only reduces one mode of cardiovascular death, leaving the competing risk of other cardiovascular, as well as non-cardiovascular causes of death. Patients with diabetes are at greater risk of noncardiovascular death than patients without diabetes, limiting the impact of any cardiovascular treatment on overall mortality. While the latter was true even in the relatively young patients enrolled in SCD-HeFT, there was only a small excess of non-cardiovascular death among individuals with diabetes. However, and more importantly, there 

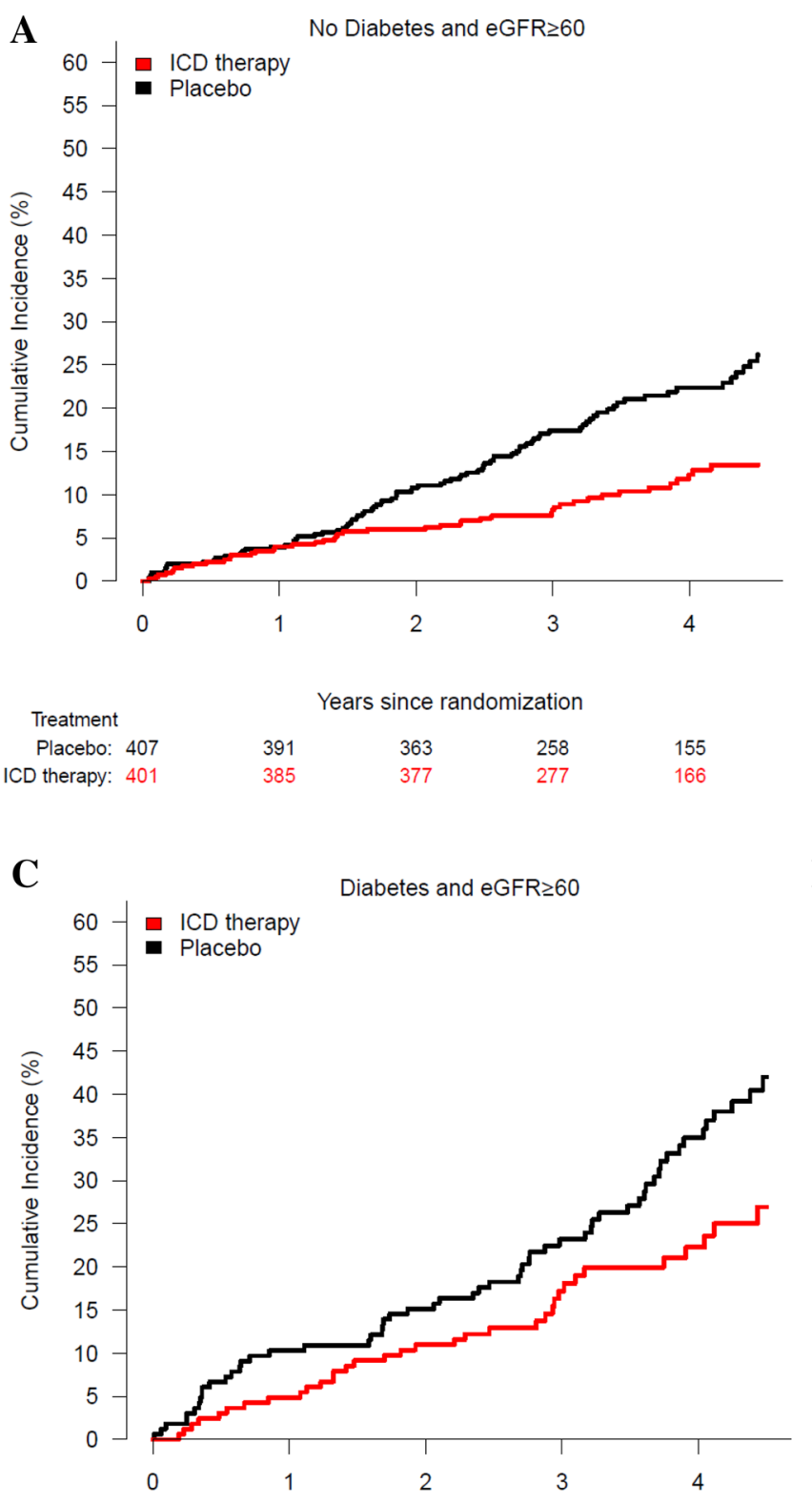
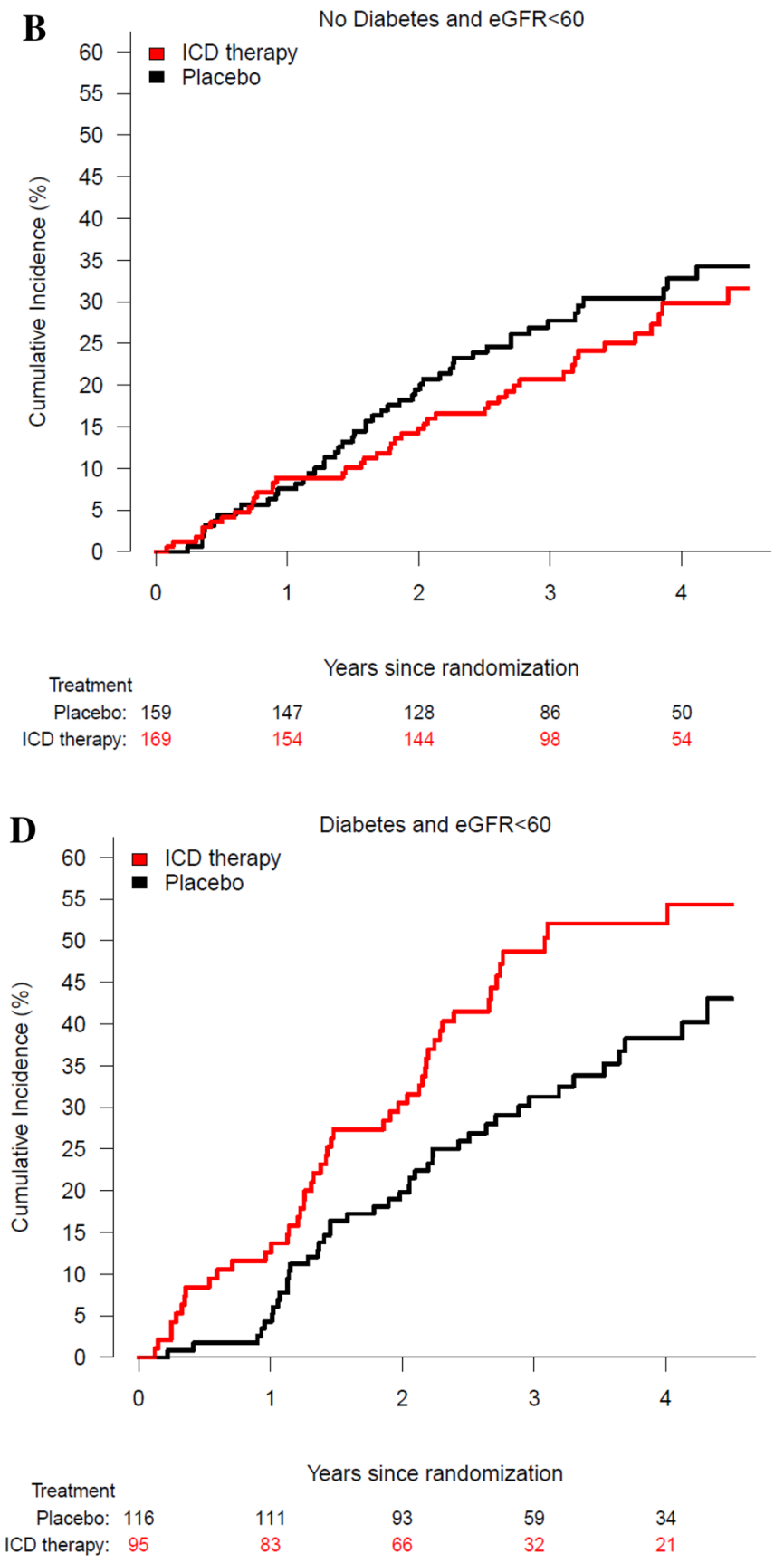

Fig. 3 Risk of death according to diabetes status and eGFR $\geq 60 \mathrm{~mL} / \mathrm{min} / 1.73 \mathrm{~m}^{2}(\mathrm{~A}+\mathrm{C})$ or eGFR $<60 \mathrm{~mL} / \mathrm{min} / 1.73 \mathrm{~m}{ }^{2}(\mathrm{~B}+\mathrm{D})$

was no evidence of a bidirectional effect of ICD therapy on different modes of cardiovascular death in patients with diabetes. Quite simply, ICD treatment was of no benefit in patients with diabetes because this therapy had no effect on sudden cardiac death (and the benefit of device therapy in patients without diabetes was attributable to the reduction in sudden cardiac death with an ICD). There was no suggestion that ICD therapy increased non-sudden cardiovascular death, particularly death from heart failure, in patients with diabetes (whereas there was some indication of this in patients without diabetes).

Because of recent debate about the value (or lack of value) of ICDs in patients with non-ischemic etiology, we also examined the interaction between diabetes status and etiology (ischemic versus non-ischemic) and effect of ICD therapy on outcomes. We found that an ICD reduced the risk of sudden death in patients without diabetes, irrespective of etiology. In patients with diabetes, ICD therapy had no effect 

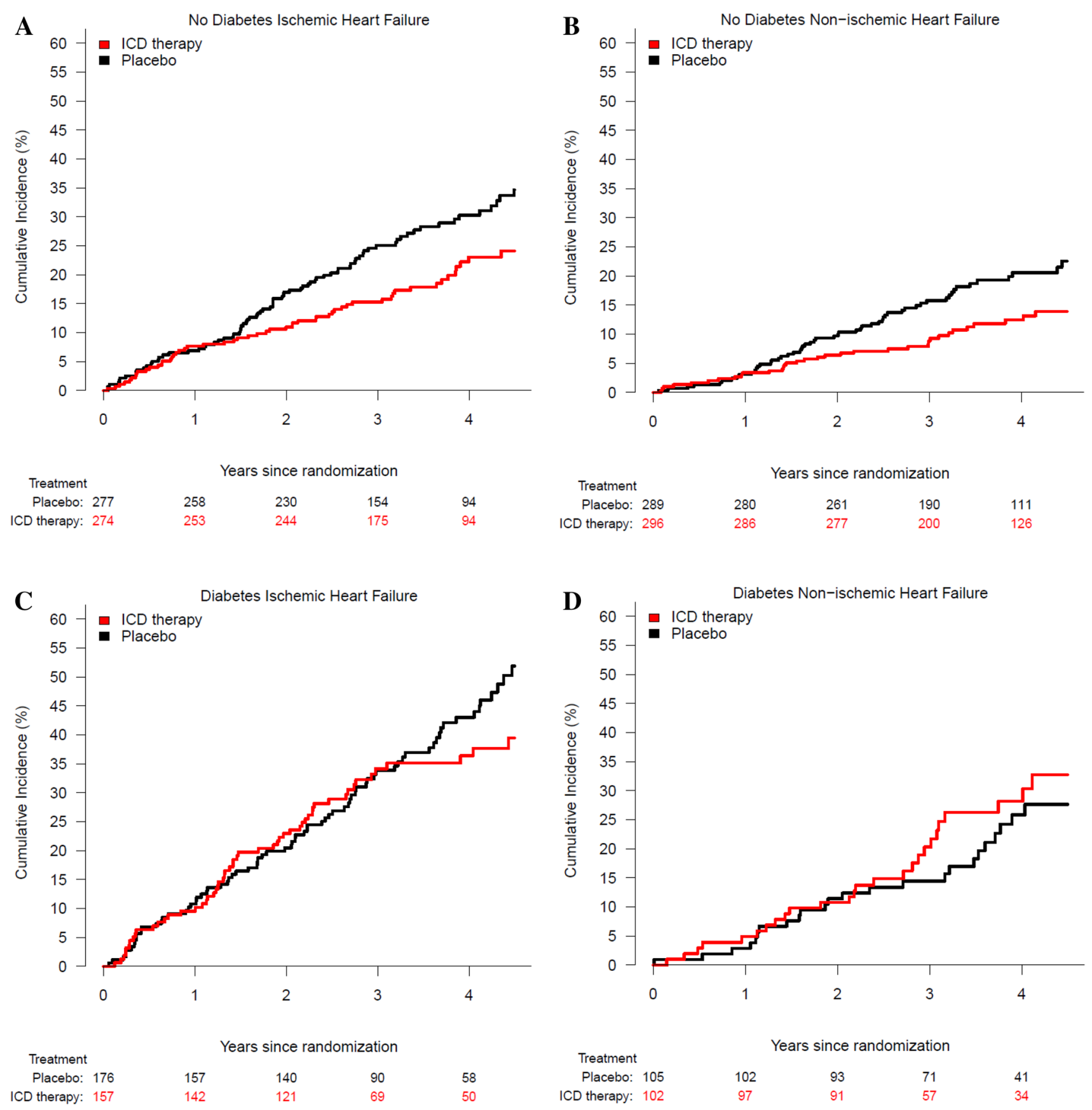

Fig. 4 Risk of death according to ischemic $(\mathrm{A}+\mathrm{C})$ and non-ischemic $(\mathrm{B}+\mathrm{D}) \mathrm{HF}$ etiology and diabetes

on sudden death, and this lack of benefit was true for both ischemic and non-ischemic etiologies. This finding is a particularly concerning for HFrEF patients with the relatively common combination of diabetes and an ischemic etiology, as they are at especially high risk of sudden cardiac death.

Assuming our findings are correct, they raise the possibility that ICDs are less effective at aborting ventricular arrhythmias in HFrEF patients with diabetes or, secondly, that a substantial proportion of adjudicated sudden cardiac deaths in HFrEF patients with diabetes are caused by mechanisms other than ventricular arrhythmias. Regarding the first possibility, comparison with the Multicenter Automatic Defibrillator Implantation Trial II (MADIT II), the pivotal ICD trial in patients after myocardial infarction is instructive [8]. In MADIT II, ICD treatment appeared to reduce all-cause mortality by a similar amount in patients with $(n=433)$ and without diabetes $(n=798)$ [9]. In other words, it was possible to show that ICDs are of benefit in 
patients with diabetes in a related, although not identical, population. If we assume most sudden deaths in chronic heart failure are caused by ventricular arrhythmias, the lack of benefit of an ICD in HFrEF patients (compared to those with myocardial infarction) suggests that development of the syndrome of symptomatic heart failure, weeks, months or years after infarction, is associated with changes in the diabetic heart, such as deposition of glycoproteins, extracellular matrix accumulation, interstitial edema, myocyte hypertrophy and myocyte loss, that attenuate the effect of electrical therapy $[10,11]$. Alternatively, the proportion of ventricular arrhythmias arising because of acute ischemia is likely to be less in chronic HFrEF than after myocardial infarction, given the much higher rate of occurrence of acute coronary syndromes in high-risk infarct survivors, compared with chronic HFrEF patients [12-17]. A further potential effectmodifier is renal function. The benefit of an ICD is known to be reduced in patients with renal impairment and HFrEF patients with diabetes have worse renal function than HFrEF patients without diabetes [18]. We observed that SCD-HeFT patients with both HFrEF and diabetes were at especially high risk and appeared to get no benefit at all from an ICD (indeed, among these patients, those with a device did worse than those without a device). However, even in patients with preserved kidney function, the benefit of an ICD was less in patients with diabetes than in those without.

Another relevant factor may be the considerable increase in LVEF over time in patients in SCD-HeFT, an increase which was slightly but significantly greater in patients with diabetes ( $+5 \%$ at 1 year), compared to those without $(+4 \%)$. By a year after randomization, $31 \%$ patients with diabetes had increased their LVEF to $>35 \%$ compared to $27 \%$ of those without diabetes. Although these differences were relatively small (and confounder by survivor bias), they may also have contributed to a lower risk of arrhythmias and less potential for benefit from an ICD in patients with diabetes.

Alternatively, a significant proportion of sudden cardiac deaths in HFrEF patients with diabetes, may not be caused by ventricular arrhythmias. In SCD-HeFT, the ICDs used were single chamber systems programmed only to shock and not to pace. Consequently, these devices did not protect against bradycardia-related events.

Another potential contributor to lack of overall benefit of ICD therapy in patients with diabetes, compared to those without, might be a greater complication rate during device implantation in individuals with diabetes, resulting in less net benefit. However, we found that the complication rate was somewhat less in patients with diabetes, compared to those without, at least in the short-term (and the overall number of complications was small). A recent pooled analysis of 4 primary prevention ICD trials, including SCD-HeFT, also reported this trend [19].
Lastly, there is the possibility that some sudden deaths in HFrEF patients with diabetes are not related to a primary cardiac arrhythmia. These may be cardiovascular in nature (such as stroke) or due to other causes such as hypoglycemia; here it is notable that $37 \%$ of patients with diabetes in SCDHeFT were treated with insulin at baseline [20,21].

One other finding in this study is worthy of comment. Amiodarone therapy, which was ineffective overall, led to a numerically higher death rate in patients with diabetes, when compared to placebo. Amiodarone did not increase mortality, compared with placebo, in patients without diabetes.

\section{Limitations}

This is a post hoc analysis and, as such, warrants caution in the interpretation of the results. One concern is the relatively small number of patients with diabetes $(n=540)$. However, the number of patients with diabetes in MADIT II was smaller and yet that trial showed a benefit of ICD therapy, suggesting that our finding of no effect was not due to lack of power [9]. A recent pooled analysis of four primary prevention trials also found no overall benefit of ICD therapy in patients with diabetes but that analysis mixed patients with HFrEF and myocardial infarction, populations with different risks of sudden and non-sudden cardiovascular death and potentially different mechanisms underlying sudden cardiac death [19]. That report did not describe the effect of ICD therapy on sudden cardiac death versus non-sudden cardiovascular death, which is crucial in understanding potentially differential effects of this treatment, i.e., an ICD can only reduce all-cause mortality by reducing sudden cardiac death (substantially) without simultaneously increasing the risk of non-sudden death.

We also did not have data on rates of device therapy and whether this was appropriate or inappropriate. However, another trial, the Multicenter Automatic Defibrillator Implantation Trial-Reduce Inappropriate Therapy trial (MADIT-RIT), demonstrated less inappropriate therapy in patients with diabetes compared to those without [22].

\section{Conclusion}

ICD therapy did not reduce the risk of sudden cardiac death (or, as a consequence, all-cause death) in HFrEF patients with diabetes. Conversely, an ICD reduced the risk of sudden death in patients without diabetes, irrespective of etiology. This may be because ICDs are less effective at aborting ventricular arrhythmias in HFrEF patients with diabetes or that some episodes of sudden death in these patients may be caused by other cardiac mechanisms (e.g., bradycardia) or non-cardiac events (e.g., hypoglycaemia). 
OpenAccess This article is distributed under the terms of the Creative Commons Attribution 4.0 International License (http://creativeco mmons.org/licenses/by/4.0/), which permits unrestricted use, distribution, and reproduction in any medium, provided you give appropriate credit to the original author(s) and the source, provide a link to the Creative Commons license, and indicate if changes were made.

\section{References}

1. Khan SS, Butler J, Gheorghiade M (2014) Management of comorbid diabetes mellitus and worsening heart failure. JAMA 311:2379-2380

2. MacDonald MR, Petrie MC, Varyani F, Ostergren J, Michelson EL, Young JB, Solomon SD, Granger CB, Swedberg K, Yusuf S, Pfeffer MA, McMurray JJ (2008) Impact of diabetes on outcomes in patients with low and preserved ejection fraction heart failure: an analysis of the Candesartan in Heart failure: assessment of reduction in mortality and morbidity $(\mathrm{CHARM})$ programme. Eur Heart J 29:1377-1385

3. Kannel WB, Hjortland M, Castelli WP (1974) Role of diabetes in congestive heart failure: the Framingham study. Am J Cardiol 34:29-34

4. Shen L, Jhund PS, Petrie MC, Claggett BL, Barlera S, Cleland JGF, Dargie HJ, Granger CB, Kjekshus J, Kober L, Latini R, Maggioni AP, Packer M, Pitt B, Solomon SD, Swedberg K, Tavazzi L, Wikstrand J, Zannad F, Zile MR, McMurray JJV (2017) Declining risk of sudden death in heart failure. N Engl J Med 377:41-51

5. Cubbon RM, Adams B, Rajwani A, Mercer BN, Patel PA, Gherardi G, Gale CP, Batin PD, Ajjan R, Kearney L, Wheatcroft SB, Sapsford RJ, Witte KK, Kearney MT (2013) Diabetes mellitus is associated with adverse prognosis in chronic heart failure of ischaemic and non-ischaemic aetiology. Diab Vasc Dis Res 10:330-336

6. Bardy GH, Lee KL, Mark DB, Poole JE, Packer DL, Boineau R, Domanski M, Troutman C, Anderson J, Johnson G, McNulty SE, Clapp-Channing N, Davidson-Ray LD, Fraulo ES, Fishbein DP, Luceri RM, Ip JH (2005) Amiodarone or an implantable cardioverter-defibrillator for congestive heart failure. N Engl J Med 352:225-237

7. Kober L, Thune JJ, Nielsen JC, Haarbo J, Videbaek L, Korup E, Jensen G, Hildebrandt P, Steffensen FH, Bruun NE, Eiskjaer H, Brandes A, Thogersen AM, Gustafsson F, Egstrup K, Videbaek R, Hassager C, Svendsen JH, Hofsten DE, Torp-Pedersen C, Pehrson S (2016) Defibrillator implantation in patients with nonischemic systolic heart failure. N Engl J Med 375:1221-1230

8. Moss AJ, Zareba W, Hall WJ, Klein H, Wilber DJ, Cannom DS, Daubert JP, Higgins SL, Brown MW, Andrews ML (2002) Prophylactic implantation of a defibrillator in patients with myocardial infarction and reduced ejection fraction. $\mathrm{N}$ Engl $\mathrm{J}$ Med 346:877-883

9. Wittenberg SM, Cook JR, Hall WJ, McNitt S, Zareba W, Moss AJ (2005) Comparison of efficacy of implanted cardioverter-defibrillator in patients with versus without diabetes mellitus. Am J Cardiol 96:417-419

10. Hardin NJ (1996) The myocardial and vascular pathology of diabetic cardiomyopathy. Coron Artery Dis 7:99-108

11. Shehadeh A, Regan TJ (1995) Cardiac consequences of diabetes mellitus. Clin Cardiol 18:301-305

12. Solomon SD, Zelenkofske S, McMurray JJV, Finn PV, Velazquez E, Ertl G, Harsanyi A, Rouleau JL, Maggioni A, Kober L, White
H, Van de Werf F, Pieper K, Califf RM, Pfeffer MA (2005) Sudden death in patients with myocardial infarction and left ventricular dysfunction, heart failure, or both. N Engl J Med 352:2581-2588

13. Dickstein K, Kjekshus J (2002) Effects of losartan and captopril on mortality and morbidity in high-risk patients after acute myocardial infarction: the OPTIMAAL randomised trial. Optimal Trial in Myocardial Infarction with Angiotensin II Antagonist Losartan. Lancet 360:752-760

14. Dargie HJ (2001) Effect of carvedilol on outcome after myocardial infarction in patients with left-ventricular dysfunction: the CAPRICORN randomised trial. Lancet 357:1385-1390

15. Kjekshus J, Apetrei E, Barrios V, Bohm M, Cleland JG, Cornel JH, Dunselman P, Fonseca C, Goudev A, Grande P, Gullestad L, Hjalmarson A, Hradec J, Janosi A, Kamensky G, Komajda M, Korewicki J, Kuusi T, Mach F, Mareev V, McMurray JJ, Ranjith N, Schaufelberger M, Vanhaecke J, van Veldhuisen DJ, Waagstein F, Wedel H, Wikstrand J (2007) Rosuvastatin in older patients with systolic heart failure. N Engl J Med 357:2248-2261

16. Effect of metoprolol CR/XL in chronic heart failure (1999) Metoprolol CR/XL randomised intervention trial in congestive heart failure (MERIT-HF). Lancet 353:2001-2007

17. Hjalmarson A, Goldstein S, Fagerberg B, Wedel H, Waagstein F, Kjekshus J, Wikstrand J, El Allaf D, Vitovec J, Aldershvile J, Halinen M, Dietz R, Neuhaus KL, Janosi A, Thorgeirsson G, Dunselman PH, Gullestad L, Kuch J, Herlitz J, Rickenbacher P, Ball S, Gottlieb S, Deedwania P (2000) Effects of controlled-release metoprolol on total mortality, hospitalizations, and well-being in patients with heart failure: the Metoprolol CR/XL Randomized Intervention Trial in congestive heart failure (MERIT-HF). MERIT-HF Study Group. JAMA 283:1295-1302

18. Pun PH, Al-Khatib SM, Han JY, Edwards R, Bardy GH, Bigger JT, Buxton AE, Moss AJ, Lee KL, Steinman R, Dorian P, Hallstrom A, Cappato R, Kadish AH, Kudenchuk PJ, Mark DB, Hess PL, Inoue LY, Sanders GD (2014) Implantable cardioverterdefibrillators for primary prevention of sudden cardiac death in CKD: a meta-analysis of patient-level data from 3 randomized trials. Am J Kidney Dis 64:32-39

19. Sharma A, Al-Khatib SM, Ezekowitz JA, Cooper LB, Fordyce CB, Michael Felker G, Bardy GH, Poole JE, Thomas Bigger J, Buxton AE, Moss AJ, Friedman DJ, Lee KL, Steinman R, Dorian P, Cappato R, Kadish AH, Kudenchuk PJ, Mark DB, Peterson ED, Inoue LYT, Sanders GD (2018) Implantable cardioverterdefibrillators in heart failure patients with reduced ejection fraction and diabetes. Eur J Heart Fail 20:1031-1038

20. Pieber TR, Marso SP, McGuire DK, Zinman B, Poulter NR, Emerson SS, Pratley RE, Woo V, Heller S, Lange M, Brown-Frandsen K, Moses A, Barner Lekdorf J, Lehmann L, Kvist K, Buse JB (2018) DEVOTE 3: temporal relationships between severe hypoglycaemia, cardiovascular outcomes and mortality. Diabetologia 61:58-65

21. Zinman B, Marso SP, Christiansen E, Calanna S, Rasmussen S, Buse JB. Hypoglycemia (2018) Cardiovascular outcomes, and death: the LEADER experience. Diabetes Care 41:1783-1791

22. Ruwald MH, Zareba W, Jons C, Zhang C, Ruwald AC, Olshansky B, McNitt S, Bloch Thomsen PE, Shoda M, Merkely B, Moss AJ, Kutyifa V (2013) Influence of diabetes mellitus on inappropriate and appropriate implantable cardioverter-defibrillator therapy and mortality in the Multicenter Automatic Defibrillator Implantation Trial-Reduce Inappropriate Therapy (MADIT-RIT) Trial. Circulation 128:694-701 